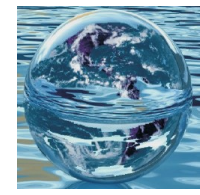

Journal homepage: $w w w$.fia.usv.ro/fiajournal Journal of Faculty of Food Engineering.

Ştefan cel Mare University of Suceava, Romania

Volume XX, Issue 2 - 2021, pag. 101 - 112

\title{
PHENOLIC CONTENT AND ATIOXIDANT ACTIVITY OF RED GRAPES FROM INTERNATIONAL, LOCAL AND HYBRID GRAPEVINE VARIETIES GROWN IN CENTRAL NORTHERN BULGARIA
}

\author{
*Dimitar DIMITROV ${ }^{\mathbf{1}}$, Tatyana YONCHEVA ${ }^{\mathbf{1}}$, Vanyo HAYGAROV ${ }^{\mathbf{1}}$, Anatoli ILIEV ${ }^{\mathbf{1}}$ \\ ${ }^{I}$ Department of Selection, Enology and Chemistry, Institute of Viticulture and Enology, \\ Pleven, Bulgaria, ilv@el-soft.com \\ dimitar_robertov@abv.bg \\ *Corresponding author \\ Received 9 March 2021, accepted 27 June 2021
}

\begin{abstract}
A study to determine the phenolic content and antioxidant activity of grapes from red international (Cabernet Sauvignon), local (Gamza) and hybrid (Rubin) grapevine varieties grown in the region of Central Northern Bulgaria was conducted. The phenolic content of the grapes, the phenolic content and antioxidant activity of their must were determined. Rubin shown the best content of Total Phenolic Compounds (TPC), Flavonoid Phenolic Compounds (FPC), Non-Flavonoid Phenolic Compounds (NPC) and anthocyanins in the structural elements of the cluster. This hybrid variety also shown the highest content of TPC in the must $(0.74 \pm 0.00 \mathrm{~g} / \mathrm{l})$, followed by Gamza, and the lowest TPC was found in the Cabernet Sauvignon - control variety $(0.25 \pm 0.00 \mathrm{~g} / \mathrm{l})$. The highest amount of anthocyanins was found in Rubin grape must $(19.91 \pm 0.48 \mathrm{mg} / \mathrm{l})$. The dynamics of increasing of the anthocyanin content in the must of the studied varieties followed the order international variety (Cabernet Sauvignon) < local variety $(G a m z a)<$ hybrid variety (Rubin). In the red varieties, the grape must of the Rubin hybrid shown significant and the highest antioxidant activity of the three studied varieties. It was four times higher than that found in the Cabernet Sauvignon control. A correlation between TPC, anthocyanin content and antioxidant activity in Rubin was found. This proved the close connection between the phenolic composition and the antioxidant capacity of the variety. The study proved that the grape must of the two studied hybrid and local varieties shown high biological potential and activities.
\end{abstract}

Keywords: antioxidant activity, grapes, phenols, free radicals, grapevine varieties.

\section{Introduction}

Antioxidants are a complex of substances a component of the foods composition, or artificially added to them. Their main function is to neutralize oxidative processes in the human body. The product of these processes are the so-called reactive oxygen species ROS (free radicals). By binding to various molecules in the body, ROS can initiate serious damages to cellular structures, leading to the formation of many diseases atherosclerosis, rheumatoid arthritis, cancer forms [1-2].

The antioxidant effect of grapes is mainly due to its phenolic complex. Phenolic compounds are localized in the solid parts - skins, bunches, seeds (source of flavonoid compounds) and fleshy part (source of non-flavonoid compounds) [3]. Flavonoid phenolic compounds are represented by catechins, proanthocyanidins, anthocyanins, flavones,

DOI: https://doi.org/10.4316/fens.2021.012 
flavonones and flavonols, while nonflavonoids include benzoic and cinnamic acids [4]. The synthesis, distribution and accumulation of phenolic compounds in grapes are highly dependent on a number of factors: the genotypic potential of the variety to accumulate phenolic substances [5-6], complex environmental influences [7], the presence of water, temperature and active access of the vine to sunlight [8] strong sun exposure is directly proportional to the degree of phenolic accumulation in the grapes [9]. The total content of phenolic compounds in red varieties occupies the range 1000.00 $5000.00 \mathrm{mg} / 1$ [10].

A study of the phenolic composition of red grapes (Cabernet Sauvignon, Merlot, Rubired and Petit Syrah) grown in Mexico found a total phenolic content of 321.90 mg GAE. $100 \mathrm{~g}^{-1}$ (Cabernet Sauvignon) to $607.60 \mathrm{mg}$ GAE. $100 \mathrm{~g}^{-1}$ (Rubired) [11]. The antioxidant activity of grapes is closely correlated with its phenolic composition. This activity plays a significant role in reducing the oxidation of LDL (low-density lipoproteins), a major factor in atherogenesis (accumulation of cholesterol plaques in blood vessels) [1213]. Grapes phenols have been shown to inhibit proliferation and apoptosis in in vitro prostate cancer cell lines [14] and exhibit strong antibacterial, antiviral, anticancer and anti-inflammatory properties [15-16].

The aim of the present study was to determine the phenolic composition and antioxidant activity of grapes from red international (Cabernet Sauvignon), local (Gamza) and hybrid (Rubin) grapevine varieties grown in the region of Central Northern Bulgaria.

\section{Matherials and methods}

\section{Grapevin varieties}

The study was conducted at the Institute of Viticulture and Enology (IVE) - Pleven (Central Northern Bulgaria). The object of the study was grapes, harvest 2020, of three red grapevine varieties international, local and hybrid:

Cabernet Sauvignon - red grapevine variety, originating form the Gironde region of France [17]. It is distributed in all wine-growing countries around the world. For the region of Pleven, Bulgaria it ripens in the second half of September. It has very good fertility, relatively droughtresistant and cold-resistant. The grapes have a high sugar accumulation (21-24\%) at relatively high titratable acidity (6.5-9.0 $\mathrm{g} / \mathrm{l})$. The wines are characterized by an intense ruby red color, specific for the variety aroma and dense taste. They are suitable for aging, during which they develop their characteristics [18-19].

Gamza - red local grapevine variety. Gamza is distributed in Hungary, Croatia and Serbia [20-22]. In Hungary, it is the main variety for the production of red table wines [23-24]. It is also widespread in small areas in Ukraine, France, Romania and some regions in Asia [25-28]. It has been grown in Bulgaria since ancient times, but has a local distribution. It was most widespread in the regions of Veliko Tarnovo, Sevlievo, Svishtov, Pleven, Lovech, Vidin and others [29]. Late ripening variety, the grapes ripens in the second half of September. The variety has a high fertility, susceptible to fungal diseases and low winter temperatures. The grapes have a sugar accumulation of 19$21 \%$ and titratable acids of 5.9-8.9 g/l.

The wines are characterized by bright red ruby color, delicate fruity aroma, young wines $[18,19,30]$.

Dimitar DIMITROV, Tatyana YONCHEVA, Vanyo HAYGAROV, Anatoli ILIEV, Phenolic content and antioxidant activity of reg grapes from international, local and hybrid grapevine varieties grown in central northern Bulgaria, Food and Environment Safety, Volume XX, Issue $2-2021$, pag. 101 112 
Rubin - a hybrid red grapevine variety. It was obtained by intraspecific hybridization by crossing Nebbiolo x Syrah [31] and approved in 1961. It was included in the Official Variety List of Bulgaria in 2012. The variety is medium ripening, and for the region of Pleven ripens in the first half of September. It has a good fertility. It is not resistant to fungal diseases, with weak resistance to low winter temperatures. The variety has a high sugar accumulation capacity of $22-24 \%$ and more, with titratable acids of 5.5-6.0 g/l. The grapes are suitable for the production of dry and dessert wines, with an intense dark red color, high extractivity and harmonious taste [18-19].

Determination of the phenolic content of grapes and must from the studied varieties

To study the phenolic content of the grapes by varieties, at the onset of technological maturity and after harvesting, their content in the structural elements of the cluster bunches, seeds, skins, berries were analyzed. For this purpose, an average sample of grapes of each variety $(2 \mathrm{~kg})$ was selected, from which $5 \mathrm{~g}$ of bunches (dried and cut into segments), $5 \mathrm{~g}$ of seeds (pre-ground in a mortar), $5 \mathrm{~g}$ of skins (predried) and $10 \mathrm{~g}$ whole berries (pre-torn in a mortar and with crushed seeds) were weighed.

The prepared and weighed quantities were transferred to Erlenmeiler flasks. Extractant $\mathrm{C}_{2} \mathrm{H}_{5} \mathrm{OH} / \mathrm{HCl}(1 \%$ v/v) was used for extraction [32].

To determine the phenolic content of the grapes (in the liquid phase, after the extraction) and the phenolic content of the must (separated immediately after crushing of the grapes) the following indicators were analyzed [32]:
- Total phenolic compounds (TPC), $\mathrm{g} / 1$ gallic acid - Singleton et Rossi method with Folin-Chiocalteu reagent

- Flavonoid phenolic compounds (FPC), mg/l catechin equivalent - Sommers method

- Non-flavonoid phenolic compounds (NPC), mg/l caffeic equivalent - Sommers method

- Anthocyanins, mg/l - method of Singleton et Rossi by changing the $\mathrm{pH}$

\section{Determination of antioxidant (DPPH •) activity of grapes and must}

The antioxidant activity was determined according to the method of Wang et al. (1996) [33], as antiradical activity against the stable product $\mathrm{DPPH} \cdot$ (2,2-diphenyl-1-picrylhydrazyl) (Sigma Aldrich, Germany). The values of the molecular light absorption (spectrophotometrically at a wavelength of $515 \mathrm{~nm}$ ) of the control and experimental sample, noted by Ac and Ae, respectively, were measured. Measurements were made at reaction times of 5 and 15 minutes from the time of the reagents mixing. The antiradical activity was calculated by the formula:

$$
\mathrm{AAR}=10^{2} \cdot(\mathrm{Ac}-\mathrm{Ae}) \cdot \mathrm{A \kappa}^{-1}, \%
$$

\section{Statistical processing}

Statistical data processing was performed, including determination of standard deviation $( \pm \mathrm{SD})$, with three repetitions for each analysis. The determination of the indicator was realized with the MS Excel 2007 from the Microsoft Package (Microsoft Corporation, USA).

\section{Results and discussion}

\section{Phenolic content of grapes}

The content of total phenolic compounds, flavonoid phenolic compounds, non flavonoid phenolic compounds and anthocyanins in the structural elements of

Dimitar DIMITROV, Tatyana YONCHEVA, Vanyo HAYGAROV, Anatoli ILIEV, Phenolic content and antioxidant activity of reg grapes from international, local and hybrid grapevine varieties grown in central northern Bulgaria, Food and Environment Safety, Volume XX, Issue $2-2021$, pag. 101 112 
the cluster - berries, skins, bunches, seeds was studied. The results are presented in Table 1.

The tendency in the content of the studied components was their increase in the order of whole berries $<$ skins $<$ bunches $<$ seeds. There were significant differences in the phenolic content of the structural elements of the cluster with TPC. The highest TPC were contained in the berries $(0.55 \pm 0.00 \mathrm{~g} / \mathrm{l})$, skins $(1.18 \pm 0.01 \mathrm{~g} / \mathrm{l}$ and seeds $(3.00 \pm 0.07 \mathrm{~g} / \mathrm{l})$ of the Rubin variety, and in the skins they were almost twice as much as in the other varieties. Gamza bunches were with the highest content of TPC $(1.89 \pm 0.00 \mathrm{~g} / \mathrm{l})$ compared to Cabernet Sauvignon and Rubin.

The FPC of Rubin variety was the highest in the berries $(1854.55 \pm 4.19 \mathrm{mg} / \mathrm{l})$, skins $(2465.66 \pm 2.63 \mathrm{mg} / \mathrm{l})$ and seeds $(6893.61$ $\pm 8.22 \mathrm{mg} / \mathrm{l})$. In the bunches of Gamza variety FPC were the highest (3247.98 \pm $3.76 \mathrm{mg} / \mathrm{l})$. Rubin berries contain FPC twice as much as Cabernet Sauvignon
(779.76 $\pm 3.45 \mathrm{mg} / \mathrm{l})$ and four times as much as Gamza $(398.33 \pm 0.82 \mathrm{mg} / \mathrm{l})$. In the skins of Rubin FPC were twice as much as Cabernet Sauvignon (1001.25 \pm $2.53 \mathrm{mg} / \mathrm{l})$ and three times more than Gamza $(841.12 \pm 3.75 \mathrm{mg} / \mathrm{l})$. In the bunches and seeds of Cabernet Sauvignon variety FPC were the lowest, respectively $1575.71 \pm 0.55 \mathrm{mg} / 1$ and $4348.75 \pm 11.93$ $\mathrm{mg} / \mathrm{l}$.

The differences in the content of NPC in the different structural parts of the cluster in the three varieties were also significant. Their quantity was significantly higher in the berries $(133.76 \pm 0.28 \mathrm{mg} / \mathrm{l})$, skins $(245.66 \pm 0.29 \mathrm{mg} / \mathrm{l})$ and seeds $(482.04 \pm$ $0.48 \mathrm{mg} / \mathrm{l}$ ) of the Rubin variety. With the exception of berries, Cabernet Sauvignon shown the lowest content of NPC in the other parts. In the skins they were three times, and in the bunches two times lower than in Rubin. Gamza variety has the lowest NPC only in the berries (47.02 \pm $0.34 \mathrm{mg} / \mathrm{l})$.

Table 1.

Phenolic content of grapes from the studied red grapevine varieties

\begin{tabular}{|c|c|c|c|c|c|}
\hline $\begin{array}{l}\text { Structural } \\
\text { elements of } \\
\text { the cluster }\end{array}$ & Indicators & Units & $\begin{array}{l}\text { Cabernet } \\
\text { Sauvignon }\end{array}$ & Gamza & Rubin \\
\hline \multirow{4}{*}{$\begin{array}{l}\text { Whole } \\
\text { berries }\end{array}$} & TPC & g/1 g.a. & $0.37 \pm 0.02$ & $0.24 \pm 0.00$ & $0.55 \pm 0.00$ \\
\hline & FPC & mg/l cat. equiv. & $779.76 \pm 3.45$ & $398.33 \pm 0.82$ & $1854.55 \pm 4.19$ \\
\hline & NPC & mg/l caf. equiv. & $62.38 \pm 10.44$ & $47.02 \pm 0.34$ & $133.76 \pm 0.28$ \\
\hline & $\begin{array}{l}\text { Anthocyanin } \\
\text { s }\end{array}$ & $\mathrm{mg} / 1$ & $154.23 \pm 0.64$ & $47.27 \pm 3.52$ & $147.40 \pm 0.16$ \\
\hline \multirow{4}{*}{ Skins } & TPC & g/1 g.a. & $0.59 \pm 0.02$ & $0.49 \pm 0.00$ & $1.18 \pm 0.01$ \\
\hline & FPC & mg/l cat. equiv. & $1001.25 \pm 2.53$ & $841.12 \pm 3.75$ & $2465.66 \pm 2.63$ \\
\hline & NPC & mg/l caf. equiv. & $80.31 \pm 0.43$ & $111.14 \pm 0.31$ & $245.66 \pm 0.29$ \\
\hline & $\begin{array}{l}\text { Anthocyanin } \\
\mathrm{s}\end{array}$ & $\mathrm{mg} / 1$ & $388.75 \pm 1.51$ & $254.19 \pm 0.44$ & $596.90 \pm 2.22$ \\
\hline \multirow{3}{*}{ Bunches } & TPC & g/1 g.a. & $1.04 \pm 0.00$ & $1.89 \pm 0.00$ & $1.76 \pm 0.01$ \\
\hline & FPC & mg/l cat. equiv. & $1575.71 \pm 0.55$ & $3247.98 \pm 3.76$ & $2983.93 \pm 1.15$ \\
\hline & NPC & mg/l caf. equiv. & $98.92 \pm 0.25$ & $172.89 \pm 0.68$ & $161.87 \pm 0.43$ \\
\hline \multirow{3}{*}{ Seeds } & TPC & g/1 g.a. & $2.15 \pm 0.01$ & $2.66 \pm 0.05$ & $3.00 \pm 0.07$ \\
\hline & FPC & mg/l cat. equiv. & $4348.75 \pm 11.93$ & $5286.14 \pm 27.10$ & $6893.61 \pm 8.22$ \\
\hline & NPC & mg/l caf. equiv. & $234.11 \pm 1.07$ & $245.82 \pm 1.33$ & $482.04 \pm 0.48$ \\
\hline
\end{tabular}

In the red grapevine varieties, the content of anthocyanins is of major importance and it is an important characteristic for the variety. In all three varieties, their content in the skins was several times higher than in the whole berries. The content in the

Dimitar DIMITROV, Tatyana YONCHEVA, Vanyo HAYGAROV, Anatoli ILIEV, Phenolic content and antioxidant activity of reg grapes from international, local and hybrid grapevine varieties grown in central northern Bulgaria, Food and Environment Safety, Volume XX, Issue $2-2021$, pag. $101-$ 112 
skins is especially important, because during the alcoholic fermentation as a result of ongoing extraction processes anthocyanins pass into the grape must. They are the main component determining the color properties of the wines. Rubin skins has the best stock of anthocyanins $(596.90 \pm 2.22 \mathrm{mg} / \mathrm{l})$, followed by Cabernet Sauvignon $(388.75 \pm 1.51 \mathrm{mg} / \mathrm{l})$, and the lowest was in Gamza (254.19 \pm $0.44 \mathrm{mg} / \mathrm{l})$. The trend in berries, however, was different. The highest content of anthocyanins was reported in Cabernet Sauvignon $(154.23 \pm 0.64 \mathrm{mg} / \mathrm{l})$, and the lowest, as well as in the skins - in the variety Gamza $(47.27 \pm 3.52 \mathrm{mg} / \mathrm{l})$.

Phenolic compounds - TPC, FPC, NPC and anthocyanins in grape must of the studied varieties

The phenolic complex is a major factor for the biological value of the grapes and wine, determining their antioxidant activities. TPC, FPC, NPC and anthocyanins were identified in the grape must of the studied varieties.

The data for TPC in grape must of the studied varieties are presented in Figure 1.

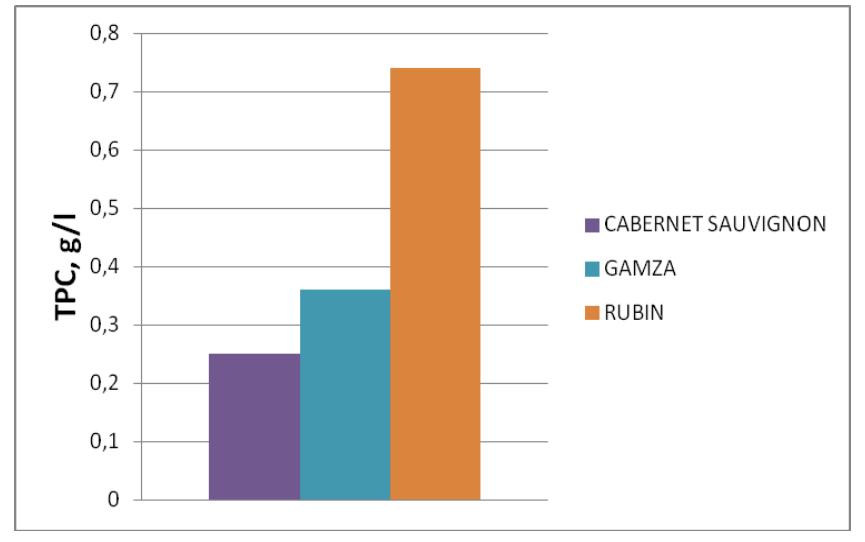

Fig. 1. Total phenolic compounds (TPC) in grape must of the studied varieties

The lowest content of TPC in the must of the control variety Cabernet Sauvignon $(0.25 \pm 0.00 \mathrm{~g} / \mathrm{l})$ was found. The results indicated that the local variety Gamza (under the soil and climatic conditions of Central Northern Bulgaria) shown a higher potential to accumulate TPC. They were found in an amount of $0.36 \pm 0.00 \mathrm{~g} / \mathrm{l}$. Very high levels of TPC shown the third studied variety - the intraspecific hybrid Rubin. TPC of $0.74 \pm 0.00 \mathrm{~g} / \mathrm{l}$ was found in its grape must. They were almost three times higher than those found in the control variety Cabernet Sauvignon.

The higher level of phenolic compounds in its must is an indirect evidence of its biological potential.
The obtained results regarding the content of FPC in grape must of the three studied varieties are presented in Figure 2.

From the results for FPC in the grape must of the three studied red grapevine varieties, a concentration in the control international variety Cabernet Sauvignon of $373.69 \pm$ $3.91 \mathrm{mg} / \mathrm{l}$ was established. FPC in the control exceeded the established amount in the other studied variety - the local Gamza. The content of FPC in its must was 129.41 $\pm 7.20 \mathrm{mg} / \mathrm{l}$. The highest levels on this indicator shown the hybrid variety Rubin. The concentration of FPC in it (832.49 \pm $12.37 \mathrm{mg} / \mathrm{l}$ ) was more than twice in comparison of that found in the must of the Cabernet Sauvignon control variety.

Dimitar DIMITROV, Tatyana YONCHEVA, Vanyo HAYGAROV, Anatoli ILIEV, Phenolic content and antioxidant activity of reg grapes from international, local and hybrid grapevine varieties grown in central northern Bulgaria, Food and Environment Safety, Volume XX, Issue 2 - 2021, pag. 101 112 
The data on the established content of nonflavonoid phenolic compounds in the grape must of the studied varieties are presented in Figure 3.

The highest concentration of NPC was found in the control Cabernet Sauvignon $(162.91 \pm 1.57 \mathrm{mg} / \mathrm{l})$. The local red variety Gamza shown the lowest concentration of NPC $(116.76 \pm 1.45 \mathrm{mg} / \mathrm{l})$. Second, after the control, by the presence of NPC was the hybrid Rubin. The NPC content of $131.57 \pm 2.37 \mathrm{mg} / \mathrm{l}$ was found in its must. Anthocyanins are red pigments in red grapevine varieties localized in their skins [3]. In the grapes they are contained in an amount of about $600.00 \mathrm{mg} / \mathrm{l}$, in the wine they are extracted from $50-70 \%$ of this amount [3].

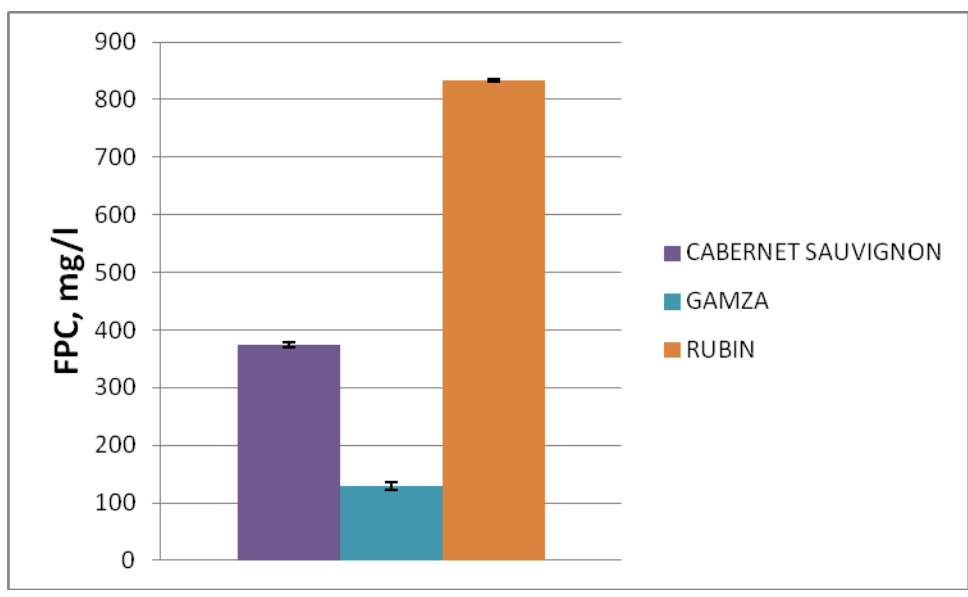

Fig. 2. Content of FPC in grape must of the studied varieties

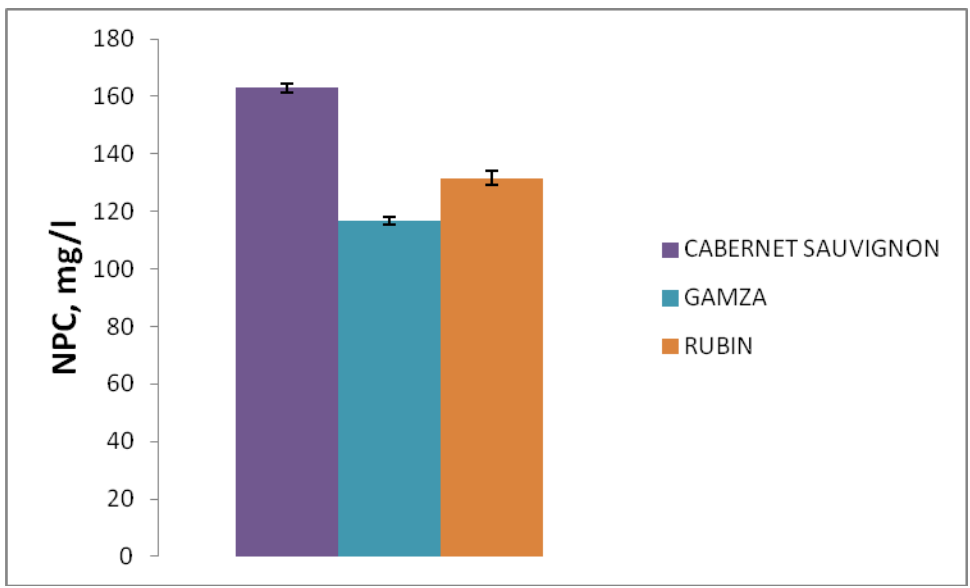

Fig. 3. Content of NPC in grape must of the studied varieties

Due to the weaker contact during crushing of the grapes (as the first phase of technological processing) in the fresh grape must, their quantities are usually low. The results obtained for their content in the grape must of the red varieties are presented in Figure 4.

From the obtained results it was clear that the international control variety Cabernet Sauvignon $(9.01 \pm 0.33 \mathrm{mg} / \mathrm{l}) \quad$ was

Dimitar DIMITROV, Tatyana YONCHEVA, Vanyo HAYGAROV, Anatoli ILIEV, Phenolic content and antioxidant activity of reg grapes from international, local and hybrid grapevine varieties grown in central northern Bulgaria, Food and Environment Safety, Volume XX, Issue $2-2021$, pag. 101 112 
characterized by the lowest content of anthocyanins. In the local variety Gamza, the amount of these phenolic components in fresh grape must was higher (11.92 \pm $0.07 \mathrm{mg} / \mathrm{l})$ than that found in the control. It was evident from the results that Rubin shown the highest concentration of anthocyanins $(19.91 \pm 0.48 \mathrm{mg} / \mathrm{l})$ from the three studied varieties, and it exceeded more than twice that found in the Cabernet Sauvignon control. In practice, a smooth dynamics of increase in the content of anthocyanins was established in the direction: introduced variety (Cabernet Sauvignon, control) $<$ local variety $($ Gamza) < hybrid variety (Rubin).

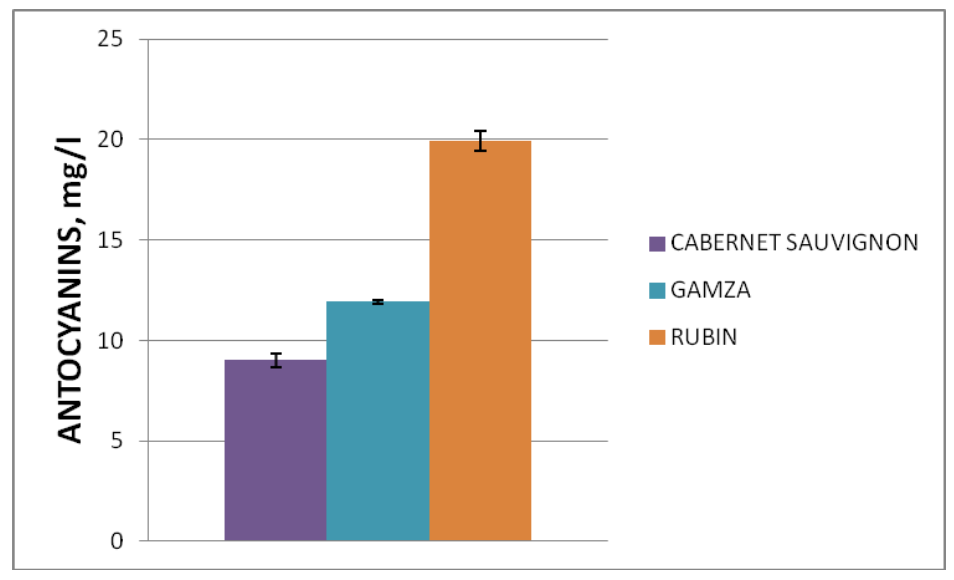

Fig. 4. Content of anthocyanins in grape must of the studied varieties

The main characteristic (as a biological effect) of anthocyanins is the proven in vitro antioxidant activity [34].

The obtained results indicated that from the three studied red grapevine varieties grown in the town of Pleven, Central Northern Bulgaria (harvest 2020) potential, in terms of anthocyanin accumulation, was the hybrid variety Rubin. The content of anthocyanins is directly related to the antioxidant capacity.

Antioxidant activity (as antiradical activity against a stable DPPH radical) in grape must of the studied red varieties

The antioxidant activity is one of the main factors determining the biological potential At $\mathrm{TE}=400.00 \mathrm{mg} / \mathrm{l}$ there was a decrease in the antioxidant capacity of Rubin. At a reaction time of $5 \mathrm{~min}$, an activity of 71.92 $\pm 0.03 \%$ was detected. At a reaction time of 15 minutes it was almost identical $71.69 \pm 0.005 \%$. of the grapes. The obtained data on the antioxidant activity (DPPH •) in grape must of the international (Cabernet Sauvignon), local (Gamza) and hybrid (Rubin) red grapevine varieties are presented in Figures 5, 6 and 7.

The highest antioxidant activity in the grape must of the red varieties was found in the hybrid variety Rubin. At $\mathrm{TE}=$ $600.00 \mathrm{mg} / 1$ and a reaction time of $5 \mathrm{~min}$, it shown antioxidant activity of $95.15 \pm$ $0.005 \%$. At a reaction time of 15 minutes, the activity of the must from this variety had a minimal change. A minimal increase was reported $-95.17 \pm 0.01 \%$.

Rubin was followed by the local variety Gamza. Its antioxidant activity, however, was many times lower than Rubin's. Gamza grape must at $\mathrm{TE}=600.00 \mathrm{mg} / \mathrm{l}$ and a reaction time of 5 min shown 36.34 $\pm 0.14 \%$ antioxidant activity. As the

Dimitar DIMITROV, Tatyana YONCHEVA, Vanyo HAYGAROV, Anatoli ILIEV, Phenolic content and antioxidant activity of reg grapes from international, local and hybrid grapevine varieties grown in central northern Bulgaria, Food and Environment Safety, Volume XX, Issue $2-2021$, pag. $101-$ 112 
reaction time increased the percentage of free radical elimination (DPPH •) increased too, with an activity of $39.75 \pm$ $0.04 \%$. In this variety with a decrease in the concentration of the total extract was registered decrease in the antioxidant activity. Thus, at $\mathrm{TE}=400.00 \mathrm{mg} / \mathrm{l}$ and a reaction time of $5 \mathrm{~min}, 22.70 \pm 0.11 \%$ elimination of DPPH was found. When the reaction time was increased to $15 \mathrm{~min}$, a slight increase in the antioxidant activity of Gamza was found $-25.96 \pm 0.06 \%$.
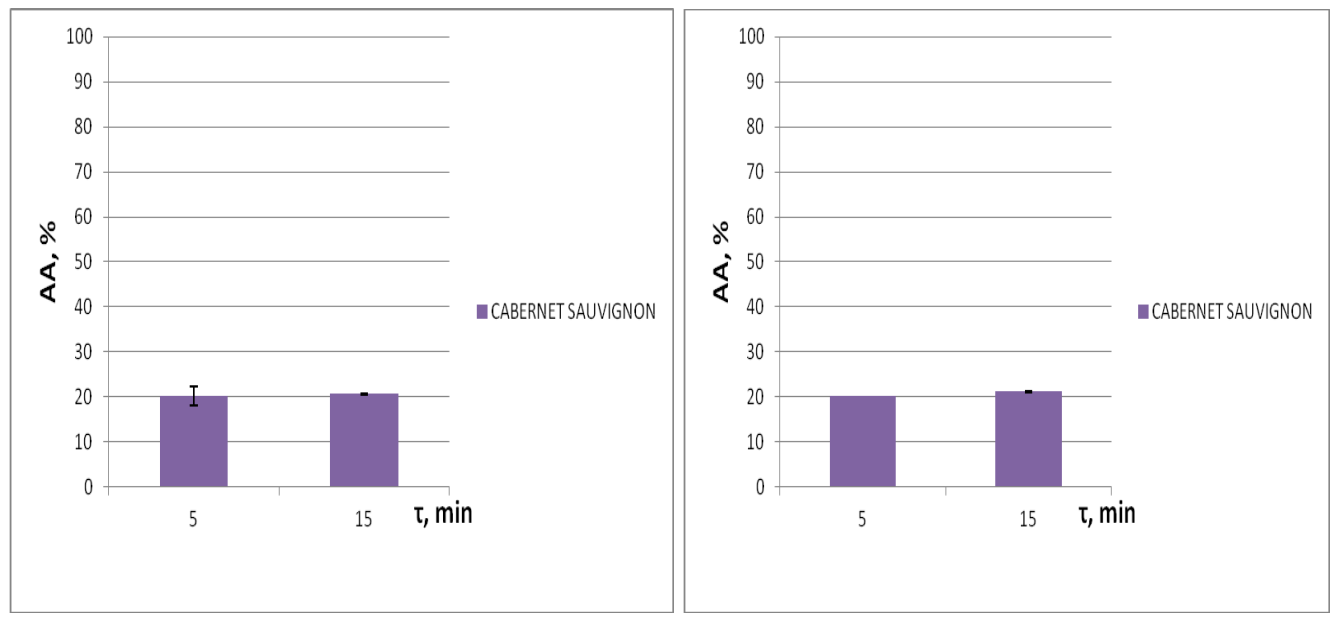

Fig. 5. Antioxidant activity of red international variety Cabernet Sauvignon at $\mathrm{TE}=600.00 \mathrm{mg} / \mathrm{l}$ and TE $=400.00 \mathrm{mg} / \mathrm{l} * \mathrm{TE}-$ Total Extract
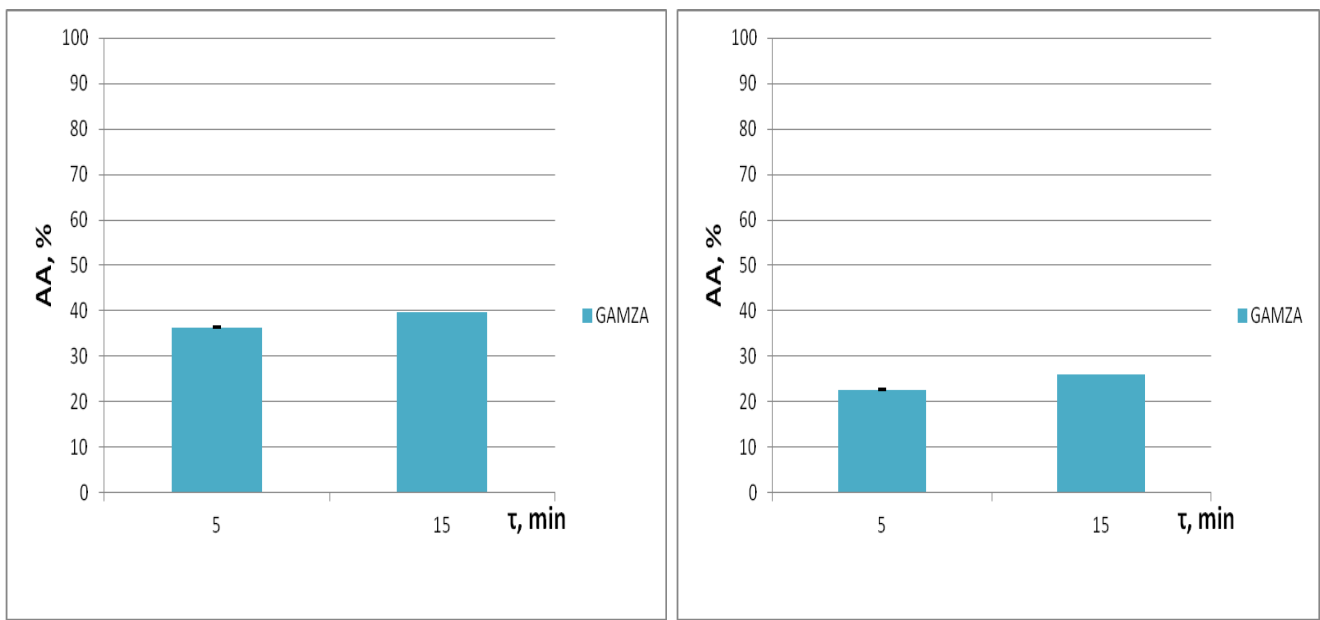

Fig. 6. Antioxidant activity of red local variety Gamza at $T E=600.00 \mathrm{mg} / \mathrm{l}$ and $\mathrm{TE}=400.00 \mathrm{mg} / \mathrm{l}$ *TE - Total Extract

Dimitar DIMITROV, Tatyana YONCHEVA, Vanyo HAYGAROV, Anatoli ILIEV, Phenolic content and antioxidant activity of reg grapes from international, local and hybrid grapevine varieties grown in central northern Bulgaria, Food and Environment Safety, Volume XX, Issue $2-2021$, pag. 101 112 

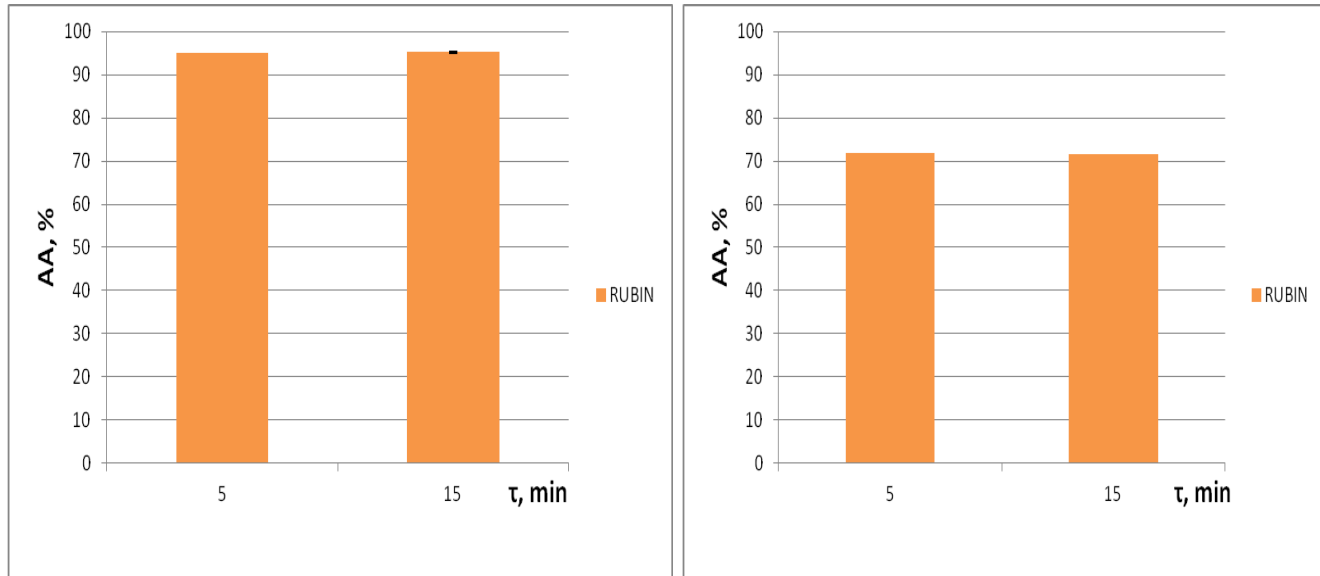

Fig. 7. Antioxidant activity of red hybrid variety Rubin at $\mathrm{TE}=600.00 \mathrm{mg} / \mathrm{l}$ and $\mathrm{TE}=400.00 \mathrm{mg} / \mathrm{l}$ *TE - Total Extract

The lowest reported antioxidant activity was observed in the control introduced Cabernet Sauvignon variety. At $\mathrm{TE}=$ $600.00 \mathrm{mg} / \mathrm{l}$ and a reaction time of $5 \mathrm{~min}$, its must shown only $20.34 \pm 2.10 \%$ elimination of the free DPPH radical. At a reaction time of 15 minutes, the same extract shown activity close to that recorded at 5 minutes of reaction $-20.70 \pm$ $0.10 \%$.

At $\mathrm{TE}=400.00 \mathrm{mg} / \mathrm{l}$ and a reaction time of 5 min, the antioxidant activity of Cabernet Sauvignon was $20.19 \pm 0.08 \%$. As the reaction time increased to 15 minutes, it increased slightly, reaching a value of $21.26 \pm 0.10 \%$

Apparently from the results obtained for the antioxidant effect of the control variety Cabernet Sauvignon was that it retained an almost constant anti-radical capacity, which was not depended on the amount of extract in the must. However, Cabernet Sauvignon grape must shown the lowest ability to eliminate DPPH - compared to the other two studied varieties.

The grape must of the Rubin hybrid shown four times higher antioxidant activity than that of Cabernet Sauvignon. Gamza's must also shown a higher antioxidant capacity than Cabernet Sauvignon, but the difference between them was significantly smaller.

The results for the antioxidant activity of grape must in red varieties fully correlated with the established content of total phenolic compounds (TPC) in them. The following dependencies have been identified:

$\mathrm{TPC}=0.25 \mathrm{~g} / 1$ (control, international variety Cabernet Sauvignon) $<\mathrm{TPC}=0.36$ $\mathrm{g} / 1$ (local variety Gamza) $<\mathrm{TPC}=0.74 \mathrm{~g} / 1$ (hybrid variety Rubin)

AA (control, international variety Cabernet Sauvignon) $<$ AA (local variety Gamza) $<$ AA (hybrid variety Rubin)

The data clearly outline the confirmed relationship between the phenolic composition of grapes and its radical scavenging ability.

The hybrid variety Rubin shown an extremely high potential for antioxidant properties, which was significantly distinguishable compared to the other two studied varieties. In addition, Rubin dominated Cabernet Sauvignon control over this specific activity.

There was also a correlation between the antioxidant activity of the must of red

Dimitar DIMITROV, Tatyana YONCHEVA, Vanyo HAYGAROV, Anatoli ILIEV, Phenolic content and antioxidant activity of reg grapes from international, local and hybrid grapevine varieties grown in central northern Bulgaria, Food and Environment Safety, Volume XX, Issue $2-2021$, pag. $101-$ 112 
varieties and their anthocyanin content. It was lowest in the Cabernet Sauvignon control, increased in the local Gamza variety, and was found in the highest amount in the Rubin hybrid. The anthocyanins are compounds with high antioxidant capacity and the present study empirically confirms the relationship between them and the antioxidant capacity of red grapevine varieties.

\section{Conclusion}

As a result of the conducted research the following conclusions could be made:

- The phenolic content of the varieties in terms of TPC, FPC, NPC and anthocyanins in the structural elements of the cluster increased in the order of whole berries < skins $<$ bunches $<$ seeds.

- Rubin has the best stock of TPC, FPC, NPC and anthocyanins. The TPC and FPC of the variety were mostly in the berries, skins and seeds, as in the skins they were almost twice as much as in the other varieties. The amount of NPC in all structural elements of the cluster of Rubin was the highest (except for the bunches). The skins of this variety has the best stock of anthocyanins, followed by Cabernet Sauvignon, and the lowest was in Gamza. In the berries, the highest content of anthocyanins was reported in Cabernet Sauvignon.

- The TPC of the grape must from the studied red grapevine varieties was the highest in the hybrid variety Rubin $(0.74 \pm$ $0.00 \mathrm{~g} / 1)$. It was followed by the local Gamza in this indicator, and the lowest amount of TPC was found in the control international variety Cabernet Sauvignon $(0.25 \pm 0.00 \mathrm{~g} / \mathrm{l})$. The Rubin hybrid demonstrated significant and high potential to accumulate phenols at the conditions of Central Northern Bulgaria.
- Rubin shown the highest quantitative presence of FPC $(832.49 \pm 12.37 \mathrm{mg} / \mathrm{l})$, twice as much as that found in the Cabernet Sauvignon control.

- The highest content of anthocyanins in the grape must of the red varieties was found in the hybrid variety Rubin (19.91 \pm $0.48 \mathrm{mg} / \mathrm{l})$. It was lowest in the Cabernet Sauvignon control. The results proved smooth growth dynamics in the content of anthocyanins in the order: international variety (Cabernet Sauvignon, control) < local variety $(\mathrm{Gamza})<$ hybrid variety (Rubin).

- In the red grapevine varieties, the grape must of the Rubin hybrid shown significant and the highest antioxidant activity of the three studied varieties. It was four times higher than that found in the Cabernet Sauvignon control. A correlation was found between TPC, anthocyanin content and antioxidant activity in Rubin. This proved the close connection between the phenolic composition and the antioxidant capacity of the variety. The grape must of the local variety Gamza also shown higher antioxidant activity compared to the Cabernet Sauvignon control, but the difference between them was significantly smaller.

\section{References}

[1]. DORMANDY T.L., An approach to free radicals, Lancet, 2: 1010-1014, (2010).

[2]. HERTOG M.G., KROMHOUT D., ARAVANIS C., BLACHBURN H., BUZINA R., FIDANZA F., GIAMPAOLI S., JANSEN A., MENOTTI A., NEDELJKOVIC S., PEKKARINEN M., SIMIC B.S., TOSHIMA H., FESKENS E.J.M., HOLLMAN P.C.H., KATAN M.B., Flavonoid intake and long-term risk of coronary heart disease and cancer in the seven countries study, Archives of Internal Medicine, 155: 381-386, (1995).

[3]. CHOBANOVA D., Manual for enology exercises, Academic Press of University of Food Technologies, Plovdiv, Bulgaria, (2007). (Bg)

Dimitar DIMITROV, Tatyana YONCHEVA, Vanyo HAYGAROV, Anatoli ILIEV, Phenolic content and antioxidant activity of reg grapes from international, local and hybrid grapevine varieties grown in central northern Bulgaria, Food and Environment Safety, Volume XX, Issue $2-2021$, pag. 101 112 
[4]. HARBONE J. B., "Plant phenolics". In Bell, E. A.; Charlwood, B. V. (eds.). Encyclopedia of Plant Physiology, volume 8 Secondary Plant Products. Berlin Heidelberg New York: SpringerVerlag. pp. 329-395, (1980).

[5]. COSTA J.M., VAZ M., ESCALONA J., EGIPTO R., LOPES C., MEDRANO H., CHAVES M.M., Modern viticulture in southern Europe: Vulnerabilities and strategies for adaptation to water scarcity, Agricultural Water Management, 164(1): 5-18, (2015).

[6]. MAZZA G., FUKUMOTO L., DELAQUIS P., GIRARD B., EWERT B., Anthocyanins, phenolics, and color of Cabernet Franc, Merlot, and Pinot Noir wines from British, Columbia Journal of Agriculture and Food Chemistry, 47: 4009-4017, (1999).

[7]. TEIXEIRA A., EIRAS-DIAS J., CASTELLARIN S.D., GERÓS H., Berry phenolics of grapevine under challenging environments, International journal of molecular sciences, 14(9): 18711-18739, (2013)

[8]. IVANOVA V., STEFOVA M., VOJNOSKI B., DORNYEI A., MARK L., DIMOVSKA V., Identification of polyphenolic compounds in red and white grape varieties grown in R. Macedonia and changes of their content during ripening, Food Research International, 44(9): 2851-2860, (2011).

[9]. ROUBELAKIS-ANGELAKIS K.A., KLIEWER W.M., Effects of exogenous factors on phenylalanine ammonia-lyase activity and accumulation of anthocyanins and total phenolics in grape berries, American Journal of Enology and Viticulture, 37: 275-280, (1986).

[10]. VELKOV E., Encyclopedia of alcoholic beverages, Ed. Polygraphy, Plovdiv, Bulgaria. ISBN 954-698-002-1, (1996).

[11]. FRANCO-BANUELOS A., GALICIAHERNÁNDE M.E., CONTRERAS-MARTÍNEZ C.S., CARRANZA-TÉLLE J., CARRANZA CONCHA J., Total phenolic content and antioxidant capacity of wine grapes grown in Zacatecas, Mexico, Investigación y Desarrollo en Ciencia y Tecnología de Alimentos, 3: 477-482, (2017).

[12]. AVIRAM M., FUHRMAN B., Wine flavonoids protect aganist LDL oxidation and atherosclerosis, Annals of New York Academy of Science, 957: 146-161, (2002).

[13]. PARTHASARATHY S., RANKIN S.M., Role of oxidized low density lipoprotein in atherogenesis, Progress in Lipid Research, 31: 127143, (1992).

[14]. ROMERO I., PAEZ A., FERRUELO A., LUJAN M., BERENGUER A., Polyphenols in red wine inhibit the proliferation and induce apoptosis of LNCaP cells, BJU International, 89: 950-954, (2002).

[15]. GRIS E.F., MATTIVI F., FERREIRA E.A., VRHOVSEK U., PEDROSA, R.C., BORDIGNON-LUIZ M.T., Proanthocyanidin profile and antioxidant capacity of Brazilian Vitis vinifera red wines, Food Chemistry, 126: 213-220, (2011).

[16]. SUN B.S., RIBES A., LEANDRO, M.C., BELCHIOR A.P., SPRANGER, M.I., Stilbenes: quantitative extraction from grape skins, contribution of grape solids to wine and variation during wine maturation, Analytica Chimica Acta, 563: 382-390, (2006).

[17]. VIALA P., VERMOREL V., Ampelographie, Vol. 2, Paris, Macon protat freres imprimeurs, 51-54, 67-69, 99-104, 139-142, (1901). [18]. RADULOV L., BABRIKOV D., GEORGIEV S. Ampelography with basics of winemaking. Sofia, Zemizdat, p. 187, (1992). (BG) [19]. ROYCHEV V., Ampelography. Plovdiv, Academic Publishing House of the Agricultural University, pp. 576, (2012). (BG)

[20]. TURCOVIC Z., Ampelografski atlas, Zagreb, Poljoprivredni nakladni zavod, 72, (1963). [21]. AVRAMOV, BRIZA K., Posebno vinogradarstvo (Ampelografia), Novi Sad, Univerzitet $u$ Novom Sadu, (1965).

[22]. ZIROJEVIC D., Poznavanje sorata vinove loze. Vol. 1, Beograd, Nolit, 15-30, 119-126, $175-$ 182, 303-310, 343-350, (1974).

[23]. CSEPREGI P., ZILAI J., Szolôfajtaink, Budapest, Mezogazdasagi, Kiado, 114-115, 218219, 224-227, 278-279, (1960).

[24]. NEMETH M., Ampelografi album, Vol. 1, Budapest, Mezogazdasagi Kiado, 157-164 (1967).

[25]. KONDAREV M., KURTEV P., TSANKOV B. and others. Ampelography, Plovdiv, "Hr. Danov", (1976).

[26]. NEDELCHEV N., GEORGIEV I., RADUCHEV S. and others., Handbook of the winemaker, Zemizdat, pp. 14, 32, 121-122.5, (1967)

[27]. BLAHA J., Ceskoslovenska ampelografi a, Bratislava, Orac, Rolnicke vydavatelstvo, 41-45, 196-200, 219-225, 284-287, (1952).

[28]. CONSTANTIUESEU G., Ampelografi a, Bucuresti, Editura agrosilvica de Stat, 193-195, 230-232, 235-236, 242-244, 250-252, 307-311, 314-317, (1958).

[29]. GEORGIEV H. Viticulture Guide, Ruse, Lithograph by Ferenc Jos Alkalay, pp. 253, 256, 267.3, (1894)

[30]. SIMEONOV I., Concise economic description of the basic local grapevine varieties for

Dimitar DIMITROV, Tatyana YONCHEVA, Vanyo HAYGAROV, Anatoli ILIEV, Phenolic content and antioxidant activity of reg grapes from international, local and hybrid grapevine varieties grown in central northern Bulgaria, Food and Environment Safety, Volume XX, Issue $2-2021$, pag. 101 112 
the Republic of Bulgaria, $P$ hytologia balcanica, 22 (2): $209-216,(2016)$.

[31]. PETKOV G., Biochemical and technological study of the varieties Bouquet, Rouen and Rubin for the production of red wines, Dissertation, Institute of Viticulture and Enology, Pleven, (1977).

[32]. STOYANOV N., Study on the phenolic compounds of grapes and wines of the varieties Cabernet Sauvignon and Mavrud. Dissertation "PhD", University of Food Technologies, Plovdiv, 35-36,

(2007).
[33]. WANG H., CAO G., PRIOR R.L., Total antioxidant capacity of fruits, Journal of Agriculture and Food Chemistry, 44(3): 701-705, (1996).

[34]. BITSCH R., NETZEL M., FRANK T., STRASS G., BITSCH I., Bioavailability and Biokinetics of Anthocyanins From Red Grape Juice and Red Wine, Journal of Biomedicine and Biotechnology, 2004 (5): 293-298, (2004).

Dimitar DIMITROV, Tatyana YONCHEVA, Vanyo HAYGAROV, Anatoli ILIEV, Phenolic content and antioxidant activity of reg grapes from international, local and hybrid grapevine varieties grown in central northern Bulgaria, Food and Environment Safety, Volume XX, Issue $2-2021$, pag. $101-$ 